Original Article

\title{
Beneficial effects of naringenin and morin on interleukin-5 and reactive oxygen species production in BALB/c mice with ovalbumin-induced asthma
}

\author{
Peng Qi, Chunhua Wei, and Dianbo Kou* \\ Department of Respiratory and Critical Care Treatment, Weifang Wei 'en Hospital, Weifang, Shandong 261031, China
}

\author{
ARTICLE INFO \\ Received May 9, 2021 \\ Revised June 22, 2021 \\ Accepted July 5, 2021 \\ *Correspondence \\ Dianbo Kou \\ E-mail:koudb1110@163.com
}

Key Words

Asthma

lonomycin

Morin

Naringenin

\begin{abstract}
We investigated the effects of naringenin and morin on IL-5 and ROS production in PMA+ionomycin-treated EL-4 cells with the corroboration of their antioxidant and anti-inflammatory properties using an asthma-induced mouse model. The EL-4 cell line was used to study the outcomes of naringenin or morin, followed by cell viability studies. Western blot analysis and ELISA test were used to determine Th2 mediated cytokines. In vivo studies were carried out on BALB/c mice to induce allergic asthma using ovalbumin administered intraperitoneally. Intracellular ROS was determined using 2',7'-dichlorodihydrofluorescein diacetate, followed by serum enzymatic (AST and ALT) estimations and inflammatory cell count in the bronchoalveolar lavage fluid (BALF) and lung tissues. Histopathological studies were conducted to examine lung tissue-stained architecture. Our findings suggested that naringenin and morin significantly suppressed IL-5 and ROS production via various pathways. Interestingly, by reducing NFAT activity, naringenin and morin stimulated HO-1 expression, thereby suppressing IL-5 secretion due to regulating the transcription factor Nrf2 via P13/Akt or ERK/JNK signalling pathways in EL-4 cells, demonstrating the involvement of $\mathrm{HO}-1$ expression in inhibiting asthmatic inflammation. The increased inflammatory cells in the BALF were substantially decreased by both naringenin and morin, followed by inhibition in the elevated Th- 2 cytokines levels. The TNF- $\alpha$ protein levels in an allergic asthma mouse model were significantly reduced by suppressing Akt phosphorylation and eosinophil formation. Recent findings confirmed that naringenin and morin possess the potential to control asthma-related immune responses through antioxidant and anti-inflammatory properties, indicating potential therapeutic agents or functional foods.
\end{abstract}

\section{INTRODUCTION}

Chronic-allergic asthma is an airway inflammation that increases the number of eosinophils and other inflammatory cells and releases pro-inflammatory mediators, promoting allergic inflammatory cells. It causes submucosal bronchial layers to vasoconstriction, leading to breathing problems [1-3]. Ovalbumininduced airway inflammation in an asthma mouse model results in increased eosinophil recruitment via T cell activation [4,5]. In addition, it results in massive secretion of Th2 cytokines regulated by transcription factors such as nuclear-activated $\mathrm{T}$ cell factor (NFAT), interleukin (IL)-13, -4 , and -5 , and tumor necrosis factor (TNF)- $\alpha$ in the lungs, blood serum, and bronchoalveolar lavage fluid (BALF) [1,2,6-8].

Allergic asthma with eosinophilic inflammation causes changes in IL-5 regulation, which facilitates the formation and (i) (5) This is an Open Access article distributed under the terms of the Creative Commons Attribution Non-Commercial License, which permits unrestricted non-commercial use, distribution, and reproduction in any medium, provided the original work is properly cited. Copyright $\odot$ Korean J Physiol Pharmacol, pISSN 1226-4512, elSSN 2093-3827
Author contributions: P.Q. designed and performed the study experiments. C.W. supervised and analysed study results. D.K. drafted and reviewed manuscript. 
differentiation of eosinophils from myeloid precursor cells $[9,10]$, but also increase reactive oxygen species (ROS) levels, including nitric oxide [11,12]. Mepolizumab is a commonly used anti-IL-5 therapy for severe allergic asthma associated with eosinophilia; however, mepolizumab intensifies asthma by causing a prolonged decrease in eosinophils with dramatic lymphocyte development [13-15], limiting its use for severe-allergic asthma. Thus, effective and safe alternatives are required for the treatment of chronic allergic asthma.

Phytonutrients such as flavonoids, found in fruit and vegetables, red wine, tea, and regular foods [16] reduce the risk of asthma [17]. Additionally, following the consumption of fruit juice and red wine, flavonoids offered a protective effect due to antioxidant activity [18]. Furthermore, a recent study identified flavonoids as potential therapeutic candidates for asthma treatment by modulating immune mediators and binding DNA sequencing factors, thus targeting oxidizing molecules [19]. Besides, a report indicated that flavonol (fisetin) suppresses the production of cytokines (IL-5) in the human cell line [20].

The molecular mechanisms of naringenin have been identified in airway inflammatory disorders such as bronchial asthma, pulmonary and cystic fibrosis, chronic obstructive pulmonary disease, and lung cancer [21-23]. It was supported with substantial inhibition of eosinophilic airway inflammation, airway hyperreactivity, and production of Th2 cytokine from CD4 T cells in ovalbumin challenged mice treated with naringenin chalcone [24]. Furthermore, hesperetin and naringenin significantly reduced lung atelectasis, airway smooth muscle hypertrophy, and sub-epithelial fibrosis in the mouse model of asthma [25]. It was also found that both naringin and naringenin might relax the tracheal smooth muscle by opening a wide $\mathrm{Ca}^{2+}$-activated $\mathrm{K}^{+}$conductance channel that mediates hyperpolarization of the plasma membrane. In addition, it decreased $\mathrm{Ca}^{2+}$ influx, suggesting a potentially productive therapeutic approach to naringin and naringenin for cough variant asthma [26]. Another study found that experimental mice with low IgE serum levels had considerably lower IL-13 and IL-4 in their bronchoalveolar lavage fluid, implying that naringenin plays a protective function in the asthma response [27,28].

Morin, a bioflavonoid similar to naringenin, demonstrated similar antitussive efficacy compared to codeine (an opioid antitussive) as a potential compound for inhibiting bronchial asthma. A study found that morin (30 and $100 \mathrm{mg} / \mathrm{kg}$ ) significantly decreased serum and BALF (IL-4 and IL-13) levels in OVALBUMIN (OVA)-sensitized guinea pigs, as well as eosinophilic lung tissue and mastocyte infiltration, similarly to that of the corticosteroid budesonide [23]. In another study, morin administration significantly reduced goblet cell hyperplasia and collagen deposition/fibrosis. In addition, morin inhibited the OVA-induced rise in IgE, TNF-, IL-4, IL-13, metalloproteinase-9 matrix, and malondialdehyde it is a potent asthmatic agent that reduces airway inflammation in chronic asthma [29].
Apart from the pertinent data from numerous published studies on naringenin and morin, it is clear that no in vitro or in vivo studies on anti-IL-5 therapy as a safe and effective treatment for severe allergic asthma associated with eosinophilia have been conducted to date. However, it is a promising treatment for severe allergic asthma associated with eosinophilia.

Therefore, the current investigation was planned to study the in vitro and in vivo effects of naringenin and morin on down-regulation of signalling pathways involving the secretion of IL-5 and ROS in EL- 4 cells induced by PMA+ionomycin through distinct pathways. The in vitro findings were further corroborated by determining asthma-dependent cytokines such as IL-13, IL-5, IL4 , and TNF- $\alpha$ for their suppressive actions on the inflammation caused airways due to allergic asthma by ovalbumin, followed by phosphorylation of mitogen-activated protein kinase and Akt, namely $\mathrm{p} 38$ and Erk1/2 in serum, BALF and lung tissue declining eosinophilic aggregation in the airways of the lung tissue caused by OVA-induced asthma in the mouse model.

\section{METHODS}

\section{Chemicals}

Citrus flavonoids (naringenin and morin, 98\% purity), PMA (phorbol 12-myristate 13-acetate), dimethyl fumarate, ionomycin, rosiglitazone and retinoic acid were purchased from Sigma Aldrich Co., Beijing, China. NFAT inhibitor was obtained from Pure Chemicals Co. (Beijing, China). Anti-(Nrf2, -NFAT), anti( $\beta$-actin, -PI3k, -Akt, -ERK, -p38, -JNK) and anti-phospho-(PI3k, -p38, -ERK, -JNK, and -Akt) were obtained Cell Signaling Technology (Beijing, China). Anti-(PPAR $\gamma$, -lamin B1, and -HO-1) antibodies were obtained from Cell Signalling Technology. horse serum, Dulbecco's modified Eagle's medium and penicillin/streptomycin antibiotics were procured from Sigma Aldrich.

\section{Cell culture}

The BCRC 60179 cell line (EL-4 murine T-lymphoma) was acquired from the research centre (Beijing, China). Modified eagle's medium (Dulbecco) was used to grow the cells supplemented by $10 \%$ horse serum. The subculture of confluent cells was carried at 1:4 with alteration of medium three times over a week with a supply of $5 \% \mathrm{CO}_{2}$ under humid room temperature.

\section{Cell viability evaluation}

The cell viability tests were carried out following previous studies [30], where the cells were treated with naringenin and morin concentrations, followed by suspension in trypan blue solution to determine cell viability. 


\section{Experimental design}

The Institution's Animal Ethics Committee (Beijing, China) approved all experimental procedures (RCC/BJ/04/2019_045). Before the experiments commenced, the $\mathrm{BALB} / \mathrm{c}$ mice (either sex eight weeks old) were allowed to maintain at $20^{\circ} \mathrm{C}-21^{\circ} \mathrm{C}$ with a 12 $\mathrm{h}$ day/night cycle in the air-conditioned facility. After a week of acclimatization, four groups of mice were formed, each with ten mice. The control (without induction of allergic-asthma) mice (n $=10)$ were orally administered distilled water $(0.5 \mathrm{ml})$.

A 3:1 ratio of ovalbumin $(700 \mu \mathrm{g} / \mathrm{ml})$ to alum $(300 \mu \mathrm{g} / \mathrm{ml})$ was prepared and adjusted to the final volume. Immunization was induced in mice $(\mathrm{n}=30)$ by intraperitoneal administration of OVA $(10 \mathrm{ml} / \mathrm{kg})$ mixed with alum on day 0 to 15 days. The ovalbuminsensitized mice were divided into three groups: allergic-asthma model, naringenin group, and morin group, each with ten mice. Ovalbumin sensitized mice with allergic asthma were given a vehicle ( $0.5 \mathrm{ml}$ of phosphate-buffered saline without OVA) between $16-28$ days together with $3 \%$ OVA $(\mathrm{w} / \mathrm{v})$ prepared in a phosphate buffer solution for $30 \mathrm{~min}$ via a nebulizer at a flow rate of $0.4 \mathrm{ml} /$ min for eight days.

However, ovalbumin sensitised mice in treatment groups $(\mathrm{n}=$ 10) were given $0.5 \mathrm{ml}$ flavonoids (naringenin and morin; prepared in phosphate-buffered saline; $100 \mathrm{mg} / \mathrm{kg} /$ day) orally from 16 to 28 days. Nevertheless, ovalbumin sensitised mice in treatment groups $(\mathrm{n}=10)$ were given $0.5 \mathrm{ml}$ flavonoids (naringenin and morin; prepared in phosphate-buffered saline; $100 \mathrm{mg} / \mathrm{kg} /$ day) orally from 16 to 28 days and were exposed to 3 percent OVA (w/v) inhalation prepared in a phosphate buffer solution for $30 \mathrm{~min}$ in a nebulizer chamber at a flow rate of $0.4 \mathrm{ml} / \mathrm{min}$.

After treatments, mice were sacrificed with ketamine injections $(2.5 \mathrm{mg} / \mathrm{kg})$ on the 30th day after fasting overnight. Blood samples were collected, followed by lavaging from the lungs with ice-cold phosphate buffer $(0.3 \mathrm{ml}$, three times). After centrifugation, the supernatant from BALF was preserved at $-80^{\circ} \mathrm{C}$ until cytokine assays were performed. The sediment-containing pellets were used for cell counting and intracellular ROS assessment. Lung tissue slices were preserved in $10 \%$ formalin solution for histological analyses.

\section{Western blot analysis and ELISA assay (enzyme-linked immunosorbent)}

The production of IL-5 in PMA+ionomycin-treated EL-4 cells was measured quantitatively for $24 \mathrm{~h}$ with and without naringenin or morin $(100 \mu \mathrm{M})$, as recommended by the ELISA kit (Sigma Aldrich). The nucleus and cytoplasmic proteins were isolated after treatment with and without naringenin or morin, as previously depicted $[31,32]$.

The lung tissues were homogenized in a phosphate buffer solution comprising RIPA lysis buffer $(100 \mathrm{mM} \mathrm{NaCl}, 3 \mathrm{mM}$ EDTA, $40 \mathrm{mM}$ Tris, 0.3 percent SDS and 3 percent Triton X-100 adjusted
$\mathrm{pH}$ to 7.5) with a blend of protease and phosphatase inhibitors. At $4^{\circ} \mathrm{C}$, the lysate was subjected for centrifugation at $15,000 \mathrm{rpm}$ for $25 \mathrm{~min}$. Protein concentration was assessed using a protein estimation kit (Sigma Aldrich), with BSA (bovine serum albumin) as the standard. In addition, the ELISA kits were employed to determine the levels of proteins such as IL-(13, -5 , and -4$)$ and TNF- $\alpha$ in the lung tissues and BALF as per the manufacturer's protocol.

The protein $(40 \mu \mathrm{g})$ were prepared for western blot analysis onto SDS-PAGE (12 per cent) gels and then placed onto the nitrocellulose membranes. The primary antibodies were bound to the membranes and incubated at $4^{\circ} \mathrm{C}$ for $12 \mathrm{~h}$. The membranes with primary antibodies were washed four times and incubated for 2 $\mathrm{h}$ with conjugated antibodies (horseradish peroxidase), followed by chemiluminescence visualization. The following NFAT, Nrf2, PPAR $\gamma$, HO-1, PI3k, Akt, ERK, JNK, p38, phospho-(PI3k, -Akt, -ERK, -JNK, -p38), lamin B1 and $\beta$-actin for the proteins isolated from PMA+ionomycin treated EL-4 cells; while Akt, phospho(Akt and -p44/42), p44/42 MAPK (Erk1/2), MAPK (p-Erk1/2), phospho-p38 MAPK, p38 MAPK and $\beta$-actin were used as primary antibodies with 1:1,000 dilution (Cell Signaling Technology).

\section{Quantification of intracellular ROS}

EL-4 cells induced by PMA+ionomycin generated intracellular ROS in the presence and absence of naringenin or morin (100 $\mu \mathrm{M})$ was determined using 2',7'- dichlorodihydrofluorescein diacetate (DCHF-DA) as described by Cheng et al. [33]. Likewise, the intracellular ROS produced from the BALF cells was measured as previously described [33], where the cells obtained from the BALF were incubated for 30 min with DCHF-DA $(100 \mu \mathrm{M})$. The cells were washed thrice using a phosphate buffer solution $(\mathrm{pH}$ 7.2), and DCF fluorescence was measured using a fluorometric microplate reader at excitation and emission wavelengths of 450 and $520 \mathrm{~nm}$.

\section{Serum alanine (ALT) and aspartate transaminases (AST) estimation}

Serum enzymes such as ALT and AST were determined after treatment with naringenin or morin $(100 \mathrm{mg} / \mathrm{kg} /$ day $)$ for one week in control mice (without asthma), positive control mice (asthma induced), and treatment groups using commercial kits (Asian pure chemical, Beijing, China).

\section{Inflammatory cell count in BALF}

The inflammatory cells count was determined, as illustrated earlier in the BALF [34]. The cells from the sediment were collected from the BALF after centrifugation. The sediment was washed with phosphate buffer solution four times and resuspended in PBS $(200 \mu \mathrm{l})$. Total cell counts were measured with a hemocy- 
tometer, and then a Diff-Quik staining reagent was employed to stabilize and stain. Different cells were counted and determined depending on their ability to stain and morphology.

\section{The histopathology of lung tissues}

The lung tissues were cut into slices ( $5 \mu \mathrm{m}$ thickness) and fixed on paraffin, followed by staining with $\mathrm{H} \& \mathrm{E}$ to examine lung tissue stained architecture.

\section{Statistical analysis}

All results were shown as mean \pm SD. ANOVA assessed significant differences, followed by the Dunnett test. A p-value of less than 0.05 was deemed significant.

\section{RESULTS}

\section{Effects of naringenin and morin on EL-4 cells induced by PMA+ionomycin}

Regulation of PMA+ionomycin mediated IL-5 and ROS production in EL-4 cells: Several studies suggested that the increase in the production of Th2 cytokine is mediated by PMA+ionomycin in EL-4 cells. Our findings (Fig. 1A, B), following several studies, showed increased development of ROS and IL-5 with PMA (150 ng / ml) plus ionomycin (500 nM) in EL- 4 cells treated for $48 \mathrm{~h}$. Besides, $150 \mathrm{ng} / \mathrm{ml}$ PMA plus $500 \mathrm{nM}$ ionomycin treated for $48 \mathrm{~h}$ was not impacted to cell viability compared with untreated cells (Fig. 1C)

Naringenin or morin inhibited NFAT protein expression regulating the IL-5 secretion: Naringenin or morin exhibited
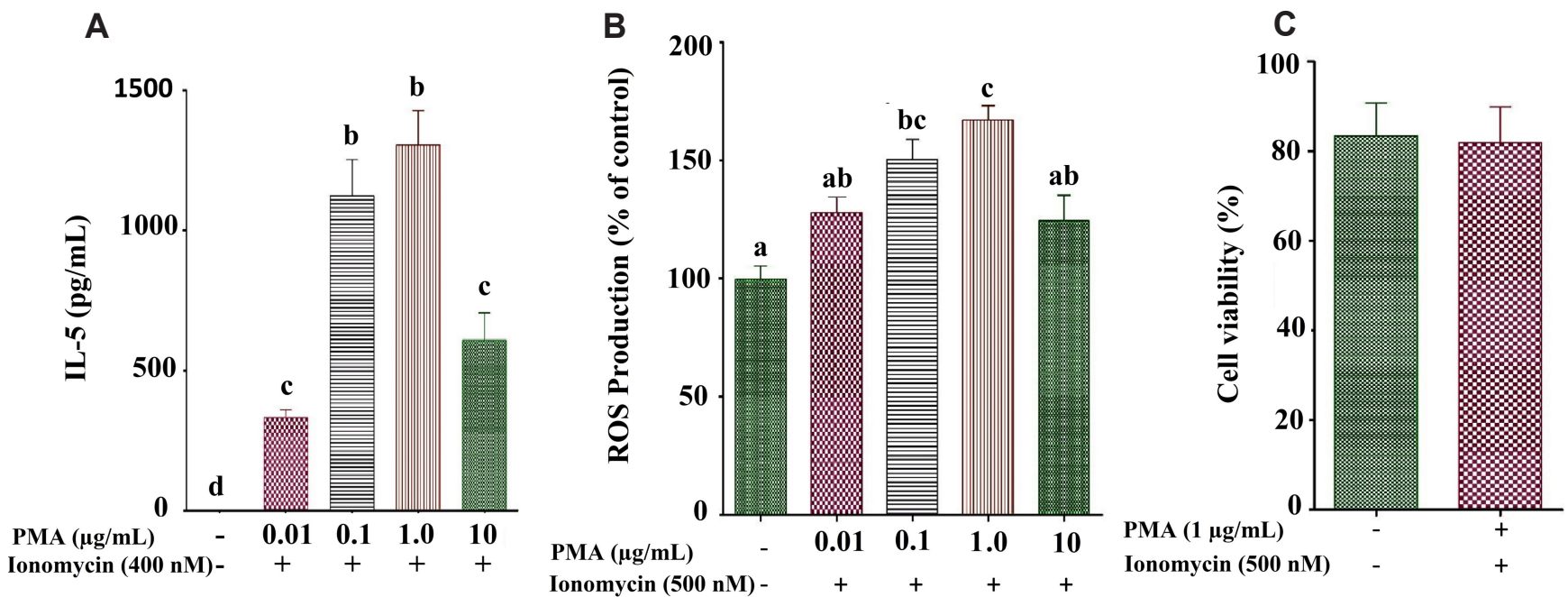

Fig. 1. Regulation of IL-5 secretion and ROS generation in PMA + ionomycin-mediated EL-4 cells. (A) IL-5 and (B) ROS were stimulated by $0-10$ $\mu \mathrm{g} / \mathrm{ml} \mathrm{PMA}$ and $500 \mathrm{nM}$ ionomycin intervention for $24 \mathrm{~h}$. (C) The viability of cells treated with $1 \mu \mathrm{g} / \mathrm{ml}$ PMA and $500 \mathrm{nM}$ ionomycin for $24 \mathrm{~h}$ was determined. The data are shown as mean \pm SD $(n=3)$. IL, interleukin; ROS, reactive oxygen species. Different letters indicate $p<0.05$ when compared to the other groups.
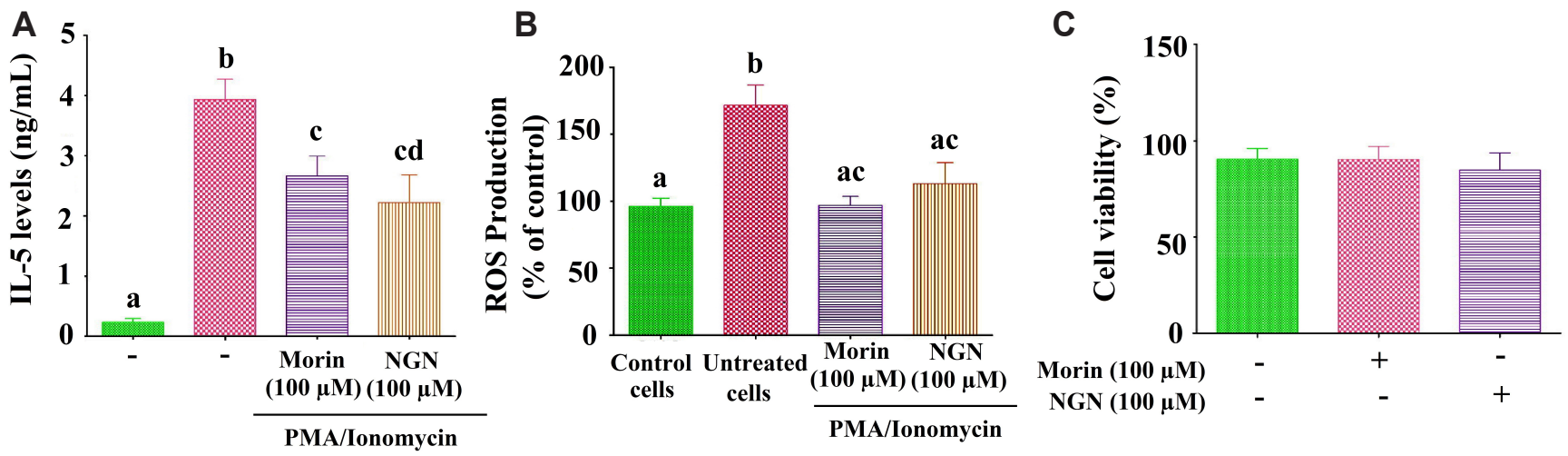

Fig. 2. Naringenin (NGN) and morin inhibited IL-5 secretion and ROS generation in EL-4 cells induced with PMA+ionomycin. Naringenin or morin and PMA+ionomycin were co-treated for $24 \mathrm{~h}$. ELISA assessed the levels of (A) IL-5 in the medium. (B) The fluorescent probe DCFH-DA (20 $\mu$ M) was used to measure ROS levels in cells. (C) Cell viability was measured after the cells were treated with naringenin or morin for $24 \mathrm{~h}$. The data is summarised as mean $\pm S D(n=3)$. IL, interleukin; ROS, reactive oxygen species. Different letters indicate $p<0.05$ when compared to every other group. 
improved anti-inflammatory and antioxidant activity; our present study, therefore, aimed to explore their suppressive actions (Fig. 2A, B) on ROS and IL-5 generation in PMA+ionomycin treated EL-4 cells $(\mathrm{p}<0.05)$. Furthermore, no substantial cytotoxic changes were observed in treated naringenin or morin cells (100 $\mu \mathrm{M}$; Fig. 2C) compared to untreated naringenin or morin cells in cell viability studies. The dose-dependent selection of doses $(50$ and $100 \mathrm{M}$ ) for the experiments using naringenin or morin was based on the inhibitory effect of NFAT (transcription factor) protein expression, which is responsible for regulating the IL-5 secretion in PMA+ionomycin treated EL-4 cells (Fig. 3).

Naringenin or morin induced heme oxygenase-1 (HO-1) expression in EL-4 cells through Nrf2 involving the signalling pathway PI3K/AKT or ERK/JNK: Fig. 4 showed increased cytosolic Nrf2 and HO-1 protein expression levels after 6-hour treatment with naringenin incubated in PMA+ionomycin-induced EL- 4 cells. Besides, Heme oxygenase-1 expression mediated through related kinases were showed to augment the phosphorylation of PI3K/Akt, ERK and c-JNK in EL-4 cells after treating with naringenin (Fig. 4). Our study findings follow the report showing upregulation of HO-1 expression in human alveolar epithelial cells treated with rosiglitazone through modulation of the transcription factor, $\mathrm{Nrf} 2$ or peroxisome proliferator-activated receptor (PPAR $\gamma)$.

Our findings further noticed that increased expression of nuclear PPAR $\gamma$ and HO-1 protein expression in PMA+ionomycin treated EL-4 cells after $6 \mathrm{~h}$ morin $(100 \mu \mathrm{M})$ treatment (Fig. 4). Furthermore, phosphorylation of related ERK kinases was increased after treatment with morin $(100 \mathrm{M})$ for $5 \mathrm{~h}$. Such results were consistent with the previously reported $\mathrm{HO}-1$ study regulated by transcription factors, namely Nrf2 or PPAR $\gamma$.

\section{Effects of naringenin and morin on ovalbumin- induced allergic asthma in a mouse model}

Total and different inflammatory BALF cells: The treatment of naringenin or morin demonstrated a dramatic $(\mathrm{p}<0.05)$ decline in the number of inflammatory total cells and eosinophils in the BALF relative to the asthma-induced group (Table 1) as compared to the control group, and the findings suggested that OVA was capable of causing inflammation of the airways in asthmainduced mice.

Intracellular ROS generation in BALF: The effect of naringenin or morin in the ovalbumin-induced asthma mice showed
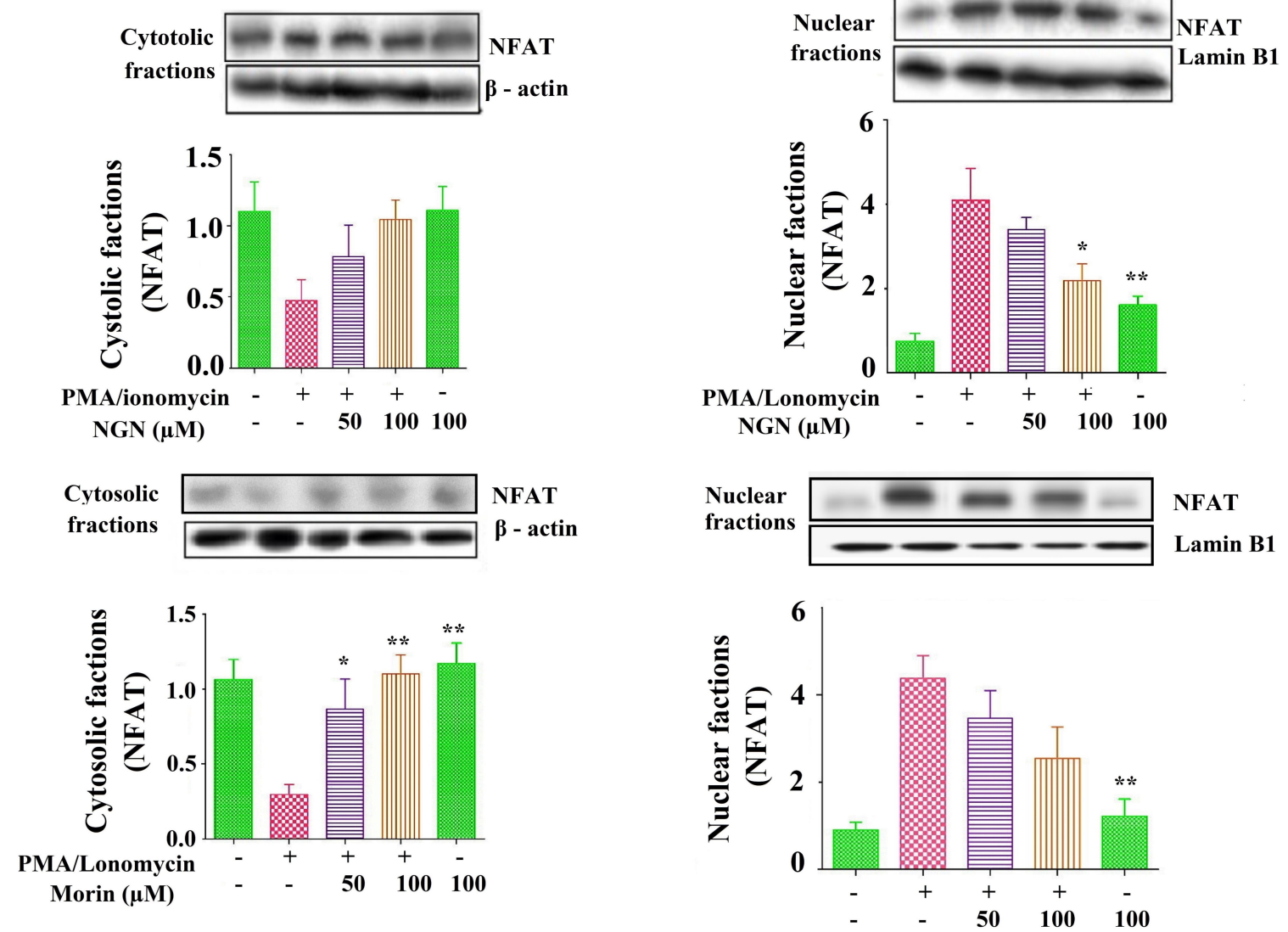

Fig. 3. Naringenin (NGN) and morin inhibited IL-5 secretion and ROS generation in EL-4 cells induced with PMA+ionomycin. Naringenin or morin, combined with PMA+ionomycin treatment, regulated cytoslic and nuclear fractions of NFAT protein expression in EL-4 cells for $24 \mathrm{~h}$. The data are shown as mean $\pm S D(n=3)$. NFAT, nuclear activated factor of T cell; IL, interleukin; ROS, reactive oxygen species. ${ }^{*}$ ndicate $p<0.05$ and ${ }^{* *}$ indicate $\mathrm{p}<0.01$ when compared to PMA+ionomycin without naringenin or morin respectively. 

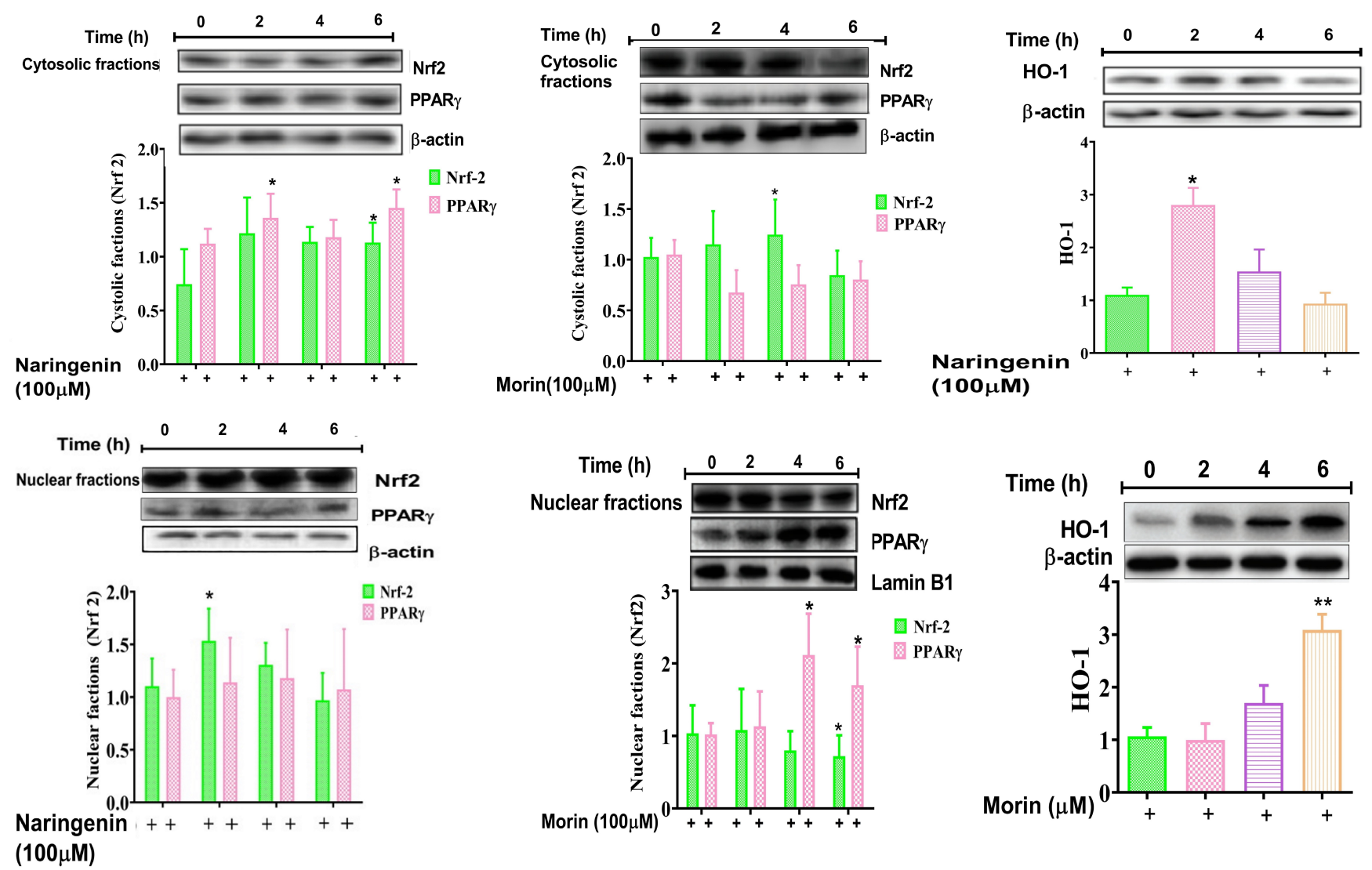

Fig. 4. Naringenin and morin decreased heme oxygenase-1 (HO-1) expression in EL-4 cells by virtue of the transcription factor Nrf2 and PPAR $\gamma$ respectively. The cells were incubated for $0,2,4$, and $6 \mathrm{~h}$ with or without $100 \mu \mathrm{M}$ of naringenin and morin respectively. Western blot analysis was used to measure the protein expression of transcription factors Nrf2 and PPAR $\gamma$ and HO-1. Data are summarized as mean \pm SD $(n=3)$. ${ }^{*} p<0.05$ and ${ }^{* *} \mathrm{p}<0.01$ compared with 0 -hr. The relative protein level is expressed as the fold changes to standardize against the control ( $\beta$-actin or Lamin B1).

Table 1. Naringenin and morin effects on the recruitment of inflammatory cells in mice's bronchoalveolar lavage fluid and stained them with the Diff-Quik stain reagent

\begin{tabular}{lrrrr}
\hline \multicolumn{1}{c}{ Cells } & \multicolumn{1}{c}{ Control } & Asthma model & Naringenin $(100 \mathrm{mg} / \mathrm{kg})$ & Morin $(100 \mathrm{mg} / \mathrm{kg})$ \\
\hline Number of cells (eosinophils) & $35.5 \pm 4.27$ & $115.8 \pm 4.84^{*}$ & $35 \pm 3.16^{* * *}$ & $35.5 \pm 3.59^{* * *}$ \\
Other inflammatory cells & $38.83 \pm 2.56$ & $414 \pm 4.52^{*}$ & $97.5 \pm 4.07^{* * *}$ & $68 \pm 4.62^{* * *}$ \\
Total cells & $40.5 \pm 3.82$ & $630.2 \pm 3.69^{*}$ & $86.17 \pm 3.95^{* * *}$ & $80.33 \pm 4.39^{* * *}$ \\
\hline
\end{tabular}

Values are expressed as mean \pm SEM $(n=10)$. Statistical significance expressed as " $\mathrm{p}<0.001$ model compared to vehicle-treated controls; ${ }^{* * *} \mathrm{p}<0.001$ naringenin and morin compared to model rats.

decreased ROS generation compared to control mice (Fig. 5), indicating ROS mechanism in bronchial airway inflammation as a significant benefit in allergic asthma.

Akt and MAPK phosphorylation pathways in lungs: Naringenin or morin's inhibitory effects on the secretion of IL-5 in PMA+ionomycin treated EL-4 cells were further corroborated with naringenin or morin's inhibitory effects on cytokine production IL- $(4,-13$, and -5$)$ and TNF- $\alpha$ through the Akt phosphorylation and MAPK signalling pathways in OVA-sensitized mice, emphasizing their role in allergic asthma (Fig. 6).

AST and ALT levels: The results of naringenin or morin demonstrated no substantial modifications in serum levels of AST and ALT between the treated and ovalbumin-induced asthma mice, thereby confirming the absence of hepatic toxicity in mice (Table 2).

BALF cytokine levels and lungs: Naringenin or morin treatment decreased significantly Th2 cytokines levels in lung tissues and BALF in OVA-induced asthma mice compared with the untreated asthma group. Besides, TNF- $\alpha$ levels in lung tissues and BALF with naringenin or morin treatment for ovalbumin-induced asthma were dramatically reduced relative to the untreated asthma group, thus corroborating the findings of production of Th2 cytokine (IL-5) after treating with naringenin or morin in PMA+ionomycin treated EL-4 cells (Fig. 7).

Histopathological changes in the lung: The findings showed asthma-induced group showed dramatic $(p<0.05)$ elevation in 
inflammatory cell infiltration relative to control mice (without induction of asthma). Nonetheless, treatment with naringenin or morin significantly reduced penetration and aggregation of inflammatory cells in the lung tissue relative to the group induced with asthma ( $\mathrm{p}<0.05$; Fig. 8$)$.

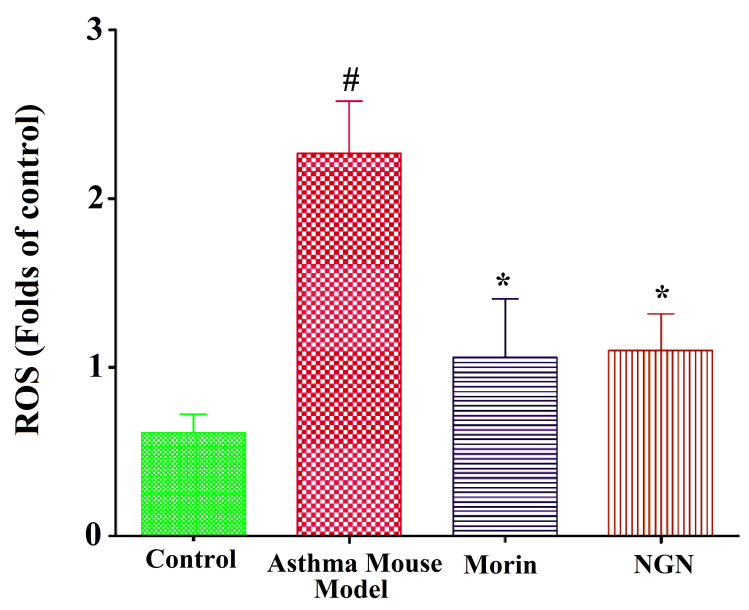

Fig. 5. Effect of naringenin (NGN) and morin on reactive oxygen species (ROS) in the bronchoalveolar lavage fluid of mice. The values are expressed as the mean \pm SEM $(n=10)$. Indicates, $p<0.05$ compared to control; ${ }^{*} p<0.05$ compared with asthma model.

\section{DISCUSSION}

Chronic allergic asthma is an airway inflammation characterized by eosinophilia [1,4], inflammatory cytokine levels like IL-5 production, and oxidative stress in cells [35-37]. Beneficial effects of citrus flavanoids are widely reported with several anti-inflammatory, antioxidant, antimicrobial and anti-endotoxemic activities in the prevention of hepatic ischemia, cardiac hypertrophy, liver steatosis and suppression of dengue virus replication [38-44]. However, the effect of naringenin and morin on inflammatory responses to asthma by inhibiting IL-5 and ROS production in PMA+ionomycin treated EL-4 cells and corroborated naringenin or morin effects OVA-induced asthma is not yet reported.

NFAT, a transcription factor, is involved in mediating cytokine secretion by Th2 responses $[7,45,46]$. A previous study showed the secretion of IL-5 modulating NFAT transcription factor in asthma patients [47]. Our results consistently showed the production of IL-5 in PMA+ionomycin treated EL-4 cells involving the regulation of NFAT (Fig. 1). Downregulation of the expression of the nuclear NFAT protein was significantly inhibited when treated with naringenin or morin $(100 \mu \mathrm{M})$, as shown in Fig. 3.

It has been shown that suppression of $\mathrm{HO}-1$ expression appears to be a novel therapeutic modulation of inflammation through the Nrf2 and MAPK signalling pathways [48]. Convincingly, our findings showed that PMA+ionomycin treated in EL-4 cells upregulated production of $\mathrm{HO}-1$ with the treatment of naringenin and morin. Interestingly, naringenin showed increased $\mathrm{HO}-1$ expressions in EL-4 cells through the transcriptional Nrf2, associ-
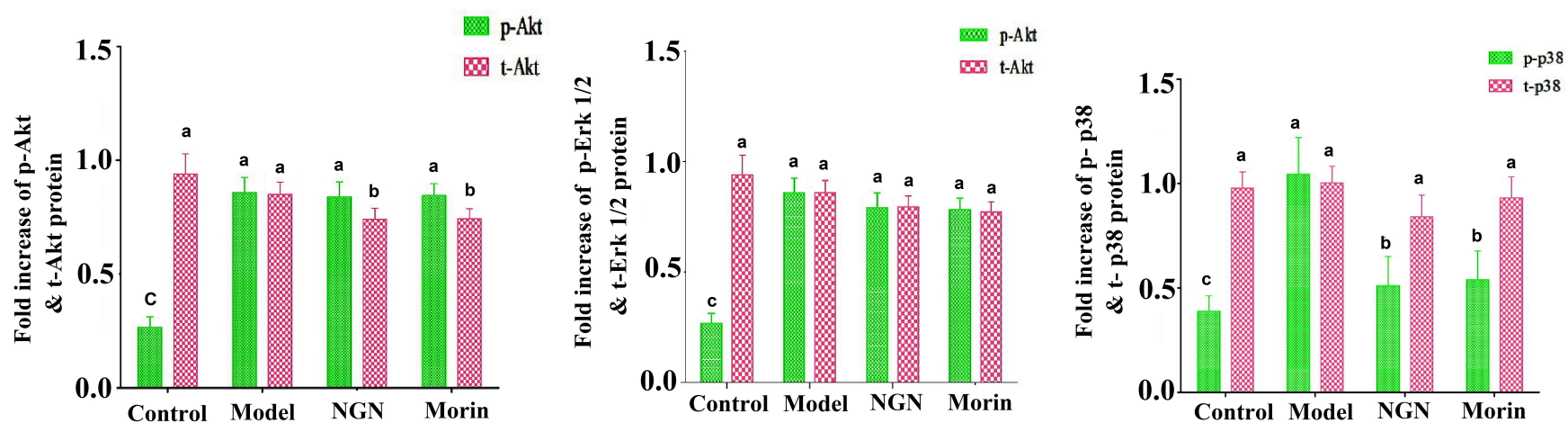

Fig. 6. Effects of naringenin (NGN) and morin on Akt and MAPK phosphorylation (Erk1/2 and p38) in mouse lung tissue. Asthma mice; Naringenin + OVA-sensitized mice and Morin + OVA-sensitized mice. The levels of p-Akt, t-Akt, p-Erk1/2, t-Erk1/2, p-p38, and t-p38 were standardized to the levels of $\beta$-actin in each sample. The values are expressed as the mean $\pm S D(n=10)$. Compared with every other group, different letters suggest $p<0.05$.

Table 2. Effects of naringenin and morin in the bronchoalveolar lavage fluid or mice serum on the levels ALT and AST

\begin{tabular}{ccccc}
\hline $\begin{array}{c}\text { Serum } \\
\text { enzymes }\end{array}$ & $\begin{array}{c}\text { Negative } \\
\text { control }\end{array}$ & $\begin{array}{c}\text { Asthma induced } \\
\text { mouse model }\end{array}$ & $\begin{array}{c}\text { Naringenin } \\
(100 \mathrm{mg} / \mathrm{kg})\end{array}$ & $\begin{array}{c}\text { Morin } \\
(100 \mathrm{mg} / \mathrm{kg})\end{array}$ \\
\hline AST $(\mathrm{U} / \mathrm{l})$ & $49.15 \pm 10.37$ & $43.38 \pm 9.79^{\mathrm{ns}}$ & $45.48 \pm 9.37^{\mathrm{ns}}$ & $48.7 \pm 12.87^{\mathrm{ns}}$ \\
ALT $(\mathrm{U} / \mathrm{l})$ & $11.25 \pm 1.48$ & $10.92 \pm 1.65^{\mathrm{ns}}$ & $10.87 \pm 1.52^{\mathrm{ns}}$ & $11.17 \pm 2.16^{\mathrm{ns}}$ \\
\hline
\end{tabular}

Values are expressed as mean \pm SEM $(n=10)$. AST, aspartate aminotransferase; ALT, alanine aminotransferase. ${ }^{\text {ns }}$ Non-significant upon comparison with every other group. 

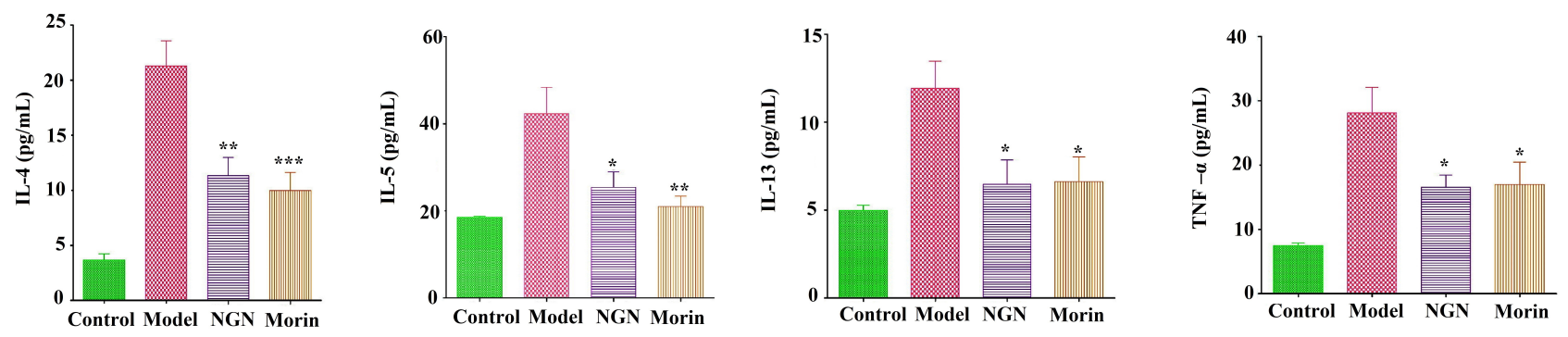

Fig. 7. The effects of naringenin (NGN) and morin on the levels of cytokines in mice's bronchoalveolar lavage fluid. Asthma mice; Naringenin + OVA-sensitized mice and Morin + OVA-sensitized mice. The values are expressed as the mean \pm SD $(n=10)$. ${ }^{*} p<0.05,{ }^{* *} p<0.01$, and ${ }^{* * *} p<0.001$ as compared to asthma model.

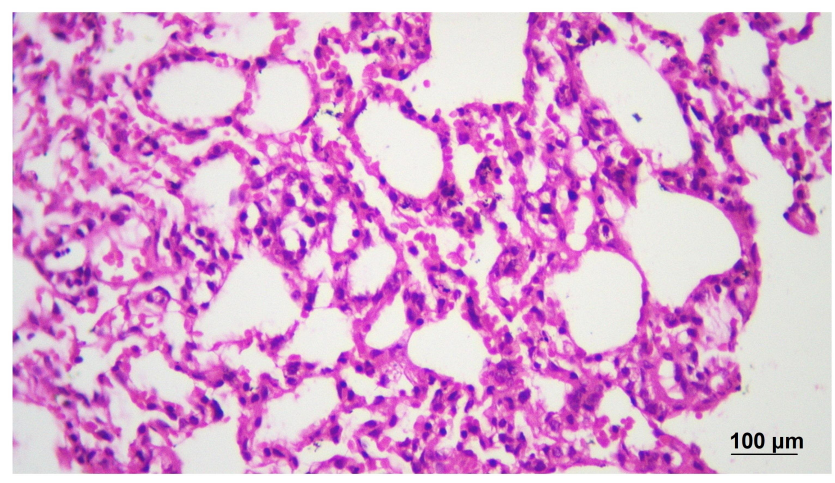

A

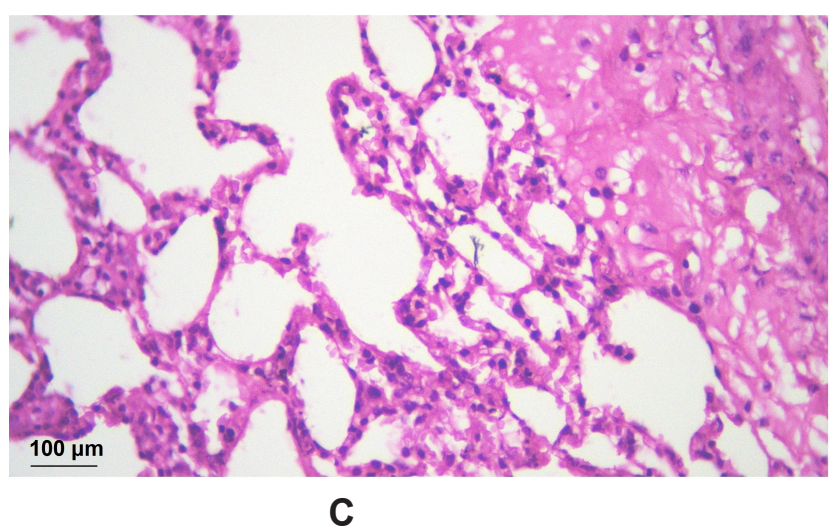

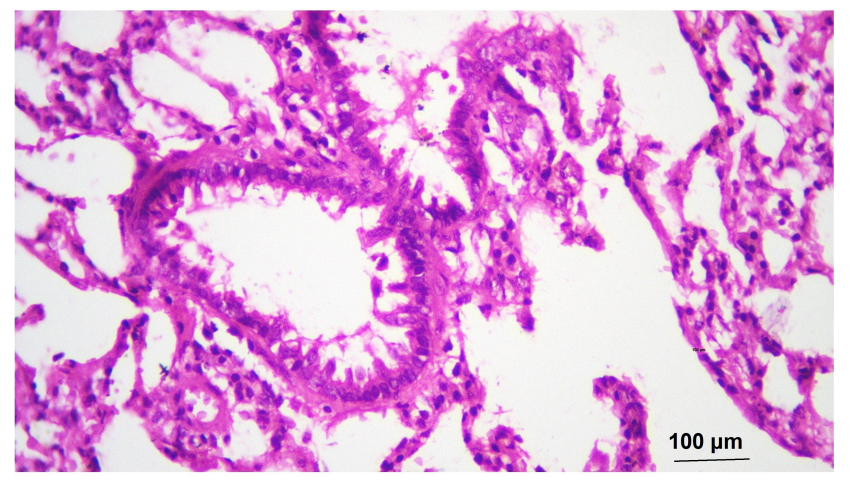

B

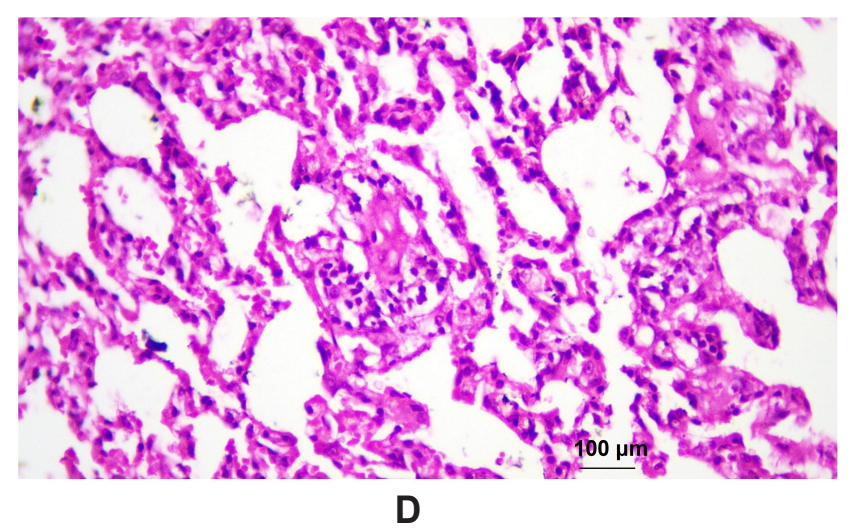

Fig. 8. Naringenin and morin interfere with cell infiltration in lung tissue, resulting in the prevention of lung inflammation. (A) Control, (B) Asthma induced mice, (C) Naringenin + OVA-sensitized mice and (D) Morin + OVA-sensitized mice. Hematoxylin and eosin staining demonstrated histopathological changes in lung tissues. Asthma induced mice; Naringenin + OVA-sensitized mice; and Morin + OVA-sensitized mice. The scale bar, 100 $\mu \mathrm{m}$.

ated with P13K/Akt or Erk/JNK signalling pathways (Fig. 4). Our findings showed that $\mathrm{HO}-1$ production was upregulated by naringenin and morin through similar signalling pathways. However, both of them (naringenin or morin) showed dramatic downregulation of the production of IL-5 through the NFAT transcription factor (Figs. 3, 4, and 7), thus suggesting that increased expression of HO-1 might suppress inflammation caused in asthma by inhibiting IL-5 production.

Naringenin and morin have anti-inflammatory and antioxidant effects on OVA-induced asthma models. However, the present study provided evidence of these effects using ovalbumin-induced airway inflammation in a mouse model of asthma to corroborate the effects of naringenin or morin on PMA+ionomycin induced EL-4 cell outcomes showing a substantial reduction in airway inflammation characteristics which include inflammatory responses, cytokine production along with suppression of ROS production.

Additionally, chronic allergic asthma involves elevation in BALF eosinophils and subsequent lung infiltration [4]. Our in vivo findings showed that naringenin or morin decreased eosino- 
philic penetration in the lungs and decreased their BALF numbers, respectively, suggesting that they possess anti-inflammatory effects in allergic asthma.

It is reported in several studies that suppression of Akt and p38 phosphorylation is the significant pathway involved in immune responses that helps in the regulation of genes related transcriptional functions of pro-inflammatory cytokines such as IL-(3, -4, $-5,-13)$ and TNF- $\alpha$ [49]. Therefore, in our study, we demonstrated that naringenin or morin suppressed the phosphorylation of Akt/ p38 pathways, thereby significantly inhibiting the Th2 cytokines production IL- $(5,-4$, and -13$)$ and TNF- $\alpha$ in the BALF and lungs, respectively, which were raised during inflammation of airway in an allergy-induced asthma mouse model. One of the allergic reaction pathways is an elevation in the secretion of IL-5 in airway inflammation that causes eosinophil infiltration into the lungs [50]. Consequently, allergic asthma can be known as Th2mediated immune disease. Therefore, these findings indicate that naringenin or morin play a vital role in suppressing eosinophils recruitment into the lungs by inhibiting Th2-medicated cytokine pathways.

Our research showed that naringenin or morin activated the Heme oxygenase-1 and Nrf2 expression through the signalling pathways involving the phosphorylation of P13K/Akt or ErK/ JNK. Such processes, therefore, contributed a significant role in suppressing NFAT expression and thus inhibiting IL-5 production in the PMA+ionomycin induced EL-4 cells. Collectively, downregulation of NFAT by Nrf2 activation had contributed to the inhibitory outcome of naringenin or morin on the generation of ROS and IL- 5 by PMA+ionomycin treatment EL- 4 cells thus confirming the stimulation of HO-1 expression could suppress asthmatic inflammatory responses by inhibiting IL-5 secretion and ROS formation. Our findings conclude that naringenin or morin can protect anti-inflammatory and antioxidant activity against allergic inflammation in asthma. Therefore, naringenin or morin could be developed as therapeutic agents or functional foods that help in allergic asthma prevention and treatment.

\section{CONFLICTS OF INTEREST}

The authors declare no conflicts of interest.

\section{REFERENCES}

1. Chung MJ, Park JK, Park YI. Anti-inflammatory effects of lowmolecular weight chitosan oligosaccharides in IgE-antigen complexstimulated RBL-2H3 cells and asthma model mice. Int Immunopharmacol. 2012;12:453-459.

2. Berend N, Salome CM, King GG. Mechanisms of airway hyperresponsiveness in asthma. Respirology. 2008;13:624-631.

3. Cockcroft DW, Davis BE. Mechanisms of airway hyperresponsive- ness. J Allergy Clin Immunol. 2006;118:551-559; quiz 560-561.

4. Gong JH, Shin D, Han SY, Kim JL, Kang YH. Kaempferol suppresses eosionphil infiltration and airway inflammation in airway epithelial cells and in mice with allergic asthma. J Nutr. 2012;142:4756.

5. Goh FY, Upton N, Guan S, Cheng C, Shanmugam MK, Sethi G, Leung BP, Wong WS. Fisetin, a bioactive flavonol, attenuates allergic airway inflammation through negative regulation of NF-кB. Eur J Pharmacol. 2012;679:109-116.

6. Hoefig KP, Heissmeyer V. Posttranscriptional regulation of T helper cell fate decisions. J Cell Biol. 2018;217:2615-2631.

7. Cousins DJ, McDonald J, Lee TH. Therapeutic approaches for control of transcription factors in allergic disease. J Allergy Clin Immunol. 2008;121:803-809; quiz 810-811.

8. Kim JJ, Cho HW, Park HR, Jung U, Jo SK, Yee ST. Preventative effect of an herbal preparation (HemoHIM) on development of airway inflammation in mice via modulation of Th1/2 cells differentiation. PLoS One. 2013;8:e68552.

9. Rothenberg ME, Hogan SP. The eosinophil. Annu Rev Immunol. 2006;24:147-174.

10. Lambrecht BN, Hammad H. The immunology of asthma. Nat Immunol. 2015;16:45-56.

11. Iijima H, Duguet A, Eum SY, Hamid Q, Eidelman DH. Nitric oxide and protein nitration are eosinophil dependent in allergen-challenged mice. Am J Respir Crit Care Med. 2001;163:1233-1240.

12. Choi Y, Le Pham D, Lee DH, Lee SH, Kim SH, Park HS. Biological function of eosinophil extracellular traps in patients with severe eosinophilic asthma. Exp Mol Med. 2018;50:1-8.

13. Stein ML, Villanueva JM, Buckmeier BK, Yamada Y, Filipovich AH, Assa'ad AH, Rothenberg ME. Anti-IL-5 (mepolizumab) therapy reduces eosinophil activation ex vivo and increases IL-5 and IL-5 receptor levels. J Allergy Clin Immunol. 2008;121:1473-1483, 1483. e1-e4.

14. Foster PS, Hogan SP, Yang M, Mattes J, Young IG, Matthaei KI, Kumar RK, Mahalingam S, Webb DC. Interleukin-5 and eosinophils as therapeutic targets for asthma. Trends Mol Med. 2002;8:162-167.

15. Haldar P, Brightling CE, Hargadon B, Gupta S, Monteiro W, Sousa A, Marshall RP, Bradding P, Green RH, Wardlaw AJ, Pavord ID. Mepolizumab and exacerbations of refractory eosinophilic asthma. N Engl J Med. 2009;360:973-984.

16. Messerli FH. Chocolate consumption, cognitive function, and Nobel laureates. N Engl J Med. 2012;367:1562-1564.

17. Garcia V, Arts IC, Sterne JA, Thompson RL, Shaheen SO. Dietary intake of flavonoids and asthma in adults. Eur Respir J. 2005;26:449452.

18. Shaheen SO, Sterne JA, Thompson RL, Songhurst CE, Margetts BM, Burney PG. Dietary antioxidants and asthma in adults: populationbased case-control study. Am J Respir Crit Care Med. 2001;164(10 Pt 1):1823-1828.

19. Mishra V, Banga J, Silveyra P. Oxidative stress and cellular pathways of asthma and inflammation: therapeutic strategies and pharmacological targets. Pharmacol Ther. 2018;181:169-182.

20. Higa S, Hirano T, Kotani M, Matsumoto M, Fujita A, Suemura M, Kawase I, Tanaka T. Fisetin, a flavonol, inhibits $\mathrm{T}_{\mathrm{H}} 2$-type cytokine production by activated human basophils. J Allergy Clin Immunol. 2003;111:1299-1306.

21. Chin LH, Hon CM, Chellappan DK, Chellian J, Madheswaran T, 
Zeeshan F, Awasthi R, Aljabali AA, Tambuwala MM, Dureja H, Negi P, Kapoor DN, Goyal R, Paudel KR, Satija S, Gupta G, Hsu A, Wark P, Mehta M, Wadhwa R, et al. Molecular mechanisms of action of naringenin in chronic airway diseases. Eur J Pharmacol. 2020;879:173139.

22. Moon PD, Choi IH, Kim HM. Naringenin suppresses the production of thymic stromal lymphopoietin through the blockade of RIP2 and caspase-1 signal cascade in mast cells. Eur J Pharmacol. 2011;671:128-132.

23. Franova S, Kazimierova I, Pappova L, Joskova M, Plank L, Sutovska M. Bronchodilatory, antitussive and anti-inflammatory effect of morin in the setting of experimentally induced allergic asthma. J Pharm Pharmacol. 2016;68:1064-1072.

24. Iwamura C, Shinoda K, Yoshimura M, Watanabe Y, Obata A, Nakayama T. Naringenin chalcone suppresses allergic asthma by inhibiting the type-2 function of CD4 T cells. Allergol Int. 2010;59:6773.

25. Seyedrezazadeh E, Kolahian S, Shahbazfar AA, Ansarin K, Pour Moghaddam M, Sakhinia M, Sakhinia E, Vafa M. Effects of the flavanone combination hesperetin-naringenin, and orange and grapefruit juices, on airway inflammation and remodeling in a murine asthma model. Phytother Res. 2015;29:591-598.

26. Shi R, Xu JW, Xiao ZT, Chen RF, Zhang YL, Lin JB, Cheng KL, Wei GY, Li PB, Zhou WL, Su WW. Naringin and Naringenin relax rat tracheal smooth by regulating $\mathrm{BK}_{\mathrm{Ca}}$ activation. J Med Food. 2019;22:963-970.

27. Shi Y, Dai J, Liu H, Li RR, Sun PL, Du Q, Pang LL, Chen Z, Yin KS. Naringenin inhibits allergen-induced airway inflammation and airway responsiveness and inhibits NF-kappaB activity in a murine model of asthma. Can J Physiol Pharmacol. 2009;87:729-735.

28. Shi Y, Tan Y, Mao S, Gu W. Naringenin inhibits allergen-induced airway remodeling in a murine model of asthma. Mol Med Rep. 2014;9:1204-1208.

29. Ma Y, Ge A, Zhu W, Liu YN, Ji NF, Zha WJ, Zhang JX, Zeng XN, Huang M. Morin attenuates ovalbumin-induced airway inflammation by modulating oxidative stress-responsive MAPK signaling. Oxid Med Cell Longev. 2016;2016:5843672.

30. Chen YH, Chen HY, Hsu CL, Yen GC. Induction of apoptosis by the Lactuca indica L. in human leukemia cell line and its active components. J Agric Food Chem. 2007;55:1743-1749.

31. Ho CY, Cheng YT, Chau CF, Yen GC. Effect of diallyl sulfide on in vitro and in vivo Nrf2-mediated pulmonic antioxidant enzyme expression via activation ERK/p38 signaling pathway. J Agric Food Chem. 2012;60:100-107.

32. Chang HY, Chen SY, Wu CH, Lu CC, Yen GC. Glycyrrhizin attenuates the process of epithelial-to-mesenchymal transition by modulating HMGB1 initiated novel signaling pathway in prostate cancer cells. J Agric Food Chem. 2019;67:3323-3332.

33. Cheng YT, Lin JA, Jhang JJ, Yen GC. Protocatechuic acid-mediated DJ-1/PARK7 activation followed by PI3K/mTOR signaling pathway activation as a novel mechanism for protection against ketoprofeninduced oxidative damage in the gastrointestinal mucosa. Free Radic Biol Med. 2019;130:35-47.

34. Altman LC, Ayars GH, Baker C, Luchtel DL. Cytokines and eosinophil-derived cationic proteins upregulate intercellular adhesion molecule-1 on human nasal epithelial cells. J Allergy Clin Immunol. 1993;92:527-536.
35. Wambre E, Bajzik V, DeLong JH, O'Brien K, Nguyen QA, Speake C, Gersuk VH, DeBerg HA, Whalen E, Ni C, Farrington M, Jeong D, Robinson D, Linsley PS, Vickery BP, Kwok WW. A phenotypically and functionally distinct human $\mathrm{T}_{\mathrm{H}} 2$ cell subpopulation is associated with allergic disorders. Sci Transl Med. 2017;9:eaam9171.

36. Nakayama T, Hirahara K, Onodera A, Endo Y, Hosokawa H, Shinoda K, Tumes DJ, Okamoto Y. $\mathrm{T}_{\mathrm{H}} 2$ cells in health and disease. Annu Rev Immunol. 2017;35:53-84.

37. Cousins DJ. Pinning allergies on pathogenic $\mathrm{T}_{\mathrm{H}} 2$ cells. Sci Transl Med. 2017;9:eaao0392.

38. Toscano-Garibay JD, Arriaga-Alba M, Sánchez-Navarrete J, Mendoza-García M, Flores-Estrada JJ, Moreno-Eutimio MA, EspinosaAguirre JJ, González-Ávila M, Ruiz-Pérez NJ. Antimutagenic and antioxidant activity of the essential oils of Citrus sinensis and Citrus latifolia. Sci Rep. 2017;7:11479.

39. Frabasile S, Koishi AC, Kuczera D, Silveira GF, Verri WA Jr, Duarte Dos Santos CN, Bordignon J. Corrigendum: The citrus flavanone naringenin impairs dengue virus replication in human cells. Sci Rep. 2017;7:43976.

40. Mosqueda-Solís A, Sánchez J, Reynés B, Palou M, Portillo MP, Palou A, Picó C. Hesperidin and capsaicin, but not the combination, prevent hepatic steatosis and other metabolic syndrome-related alterations in Western diet-fed rats. Sci Rep. 2018;8:15100.

41. Park JH, Ku HJ, Kim JK, Park JW, Lee JH. Amelioration of high fructose-induced cardiac hypertrophy by Naringin. Sci Rep. 2018;8: 9464.

42. Liu X, Wang N, Fan S, Zheng X, Yang Y, Zhu Y, Lu Y, Chen Q, Zhou $\mathrm{H}$, Zheng J. The citrus flavonoid Naringenin confers protection in a murine endotoxaemia model through AMPK-ATF3-dependent negative regulation of the TLR4 signalling pathway. Sci Rep. 2016;6:39735.

43. Dusabimana T, Kim SR, Kim HJ, Park SW, Kim H. Nobiletin ameliorates hepatic ischemia and reperfusion injury through the activation of SIRT-1/FOXO3a-mediated autophagy and mitochondrial biogenesis. Exp Mol Med. 2019;51:1-16.

44. Anwar A, Masri A, Rao K, Rajendran K, Khan NA, Shah MR, Siddiqui R. Antimicrobial activities of green synthesized gums-stabilized nanoparticles loaded with flavonoids. Sci Rep. 2019;9:3122.

45. Fric J, Zelante T, Wong AY, Mertes A, Yu HB, Ricciardi-Castagnoli P. NFAT control of innate immunity. Blood. 2012;120:1380-1389.

46. Crabtree GR, Olson EN. NFAT signaling: choreographing the social lives of cells. Cell. 2002;109 Suppl:S67-S79.

47. Ogawa K, Kaminuma O, Okudaira H, Kikkawa H, Ikezawa K, Sakurai N, Mori A. Transcriptional regulation of the IL-5 gene in peripheral T cells of asthmatic patients. Clin Exp Immunol. 2002;130:475483.

48. Wang C, Choi YH, Xian Z, Zheng M, Piao H, Yan G. Aloperine suppresses allergic airway inflammation through NF- $\mathrm{B}, \mathrm{MAPK}$, and $\mathrm{Nrf} 2 / \mathrm{HO}-1$ signaling pathways in mice. Int Immunopharmacol. 2018;65:571-579.

49. Chung MJ, Sohng JK, Choi DJ, Park YI. Inhibitory effect of phloretin and biochanin A on IgE-mediated allergic responses in rat basophilic leukemia RBL-2H3 cells. Life Sci. 2013;93:401-408.

50. Hazlewood LC, Wood LG, Hansbro PM, Foster PS. Dietary lycopene supplementation suppresses $\mathrm{T}_{\mathrm{H}} 2$ responses and lung eosinophilia in a mouse model of allergic asthma. J Nutr Biochem. 2011;22:95-100. 